\title{
Self-Retraction Clamp for Dissection of the Posterior Prostatic Fossa During Radical Retropubic Prostatectomy
}

\author{
Aria F. Olumi, M.D. \\ Brigham \& Womenís Hospital, Harvard Medical School, Boston, MA 02115 \\ E-mail: aolumi@caregroup.harvard.edu \\ Previously published in the Digital Urology Journal
}

DOMAIN: urology

\section{INTRODUCTION}

Dissection of the posterior prostatic fossa is a critical part of radical retropubic prostatectomy (RRP). Two main goals during this portion of surgery are 1. to identify the correct plane on the anterior wall of the rectum to ensure all layers of Denonvilliers fascia are excised, and 2. to avoid trauma to the neurovascular bundle ${ }^{1}$. After resection of the anterior urethra, the Foley catheter is brought through, clamped and divided, followed by incision of the posterior urethral wall. With the aid of a hemostat clamp on the divided Foley catheter, the prostate is retracted cranially to dissect the lateral pelvic fascia and identify the neurovascular bundle. However, manual cranial retraction of the prostate is imprecise; too much retraction can damage the neurovascular bundle, and too little retraction does not delineate the fascial planes between the prostate and the rectum. Therefore, a self-retraction prostate clamp was designed to enable the surgeon to apply constant traction on the Foley catheter during dissection of the posterior prostatic fossa during RRP. (The prostate self-retraction clamp can be purchased from: J Hugh Knight Instrument Company, 226 S. Villere St., New Orleans, LA 70112, 504-524-2797.)

\section{TECHNIQUE}

The clamp is divided into three portions, segments A and B connected by a $20 \mathrm{~cm}$ ball-bearing chain (Figure 1). Prior to resection of the Foley catheter, the catheter is clamped with segment A of the retraction device. Segment A of the retraction clamp secures the catheter without sliding and the toothed segment (arrow Figure 1) limits the maximum applied pressure on the Foley catheter in order to avoid damaging the balloon port. Segment B is attached to the Bookwalter ring or the Balfour retractor. The tension on the chain is adjusted by cocking the ball-bearing chain in the notched screw of segment B (dashed arrow Figure 1, and Figure 2). By using the self-retraction device, the clamp is adjusted on the Bookwalter or the Balfour ring only twice (once for each posterior prostatic pedicle). The rest of the adjustments simply are by varying the length in the "ball-bearing" chain as the dissection of the posterior prostatic fossa is continued cranially. The length of the ball-bearing chain is adjusted to vary the applied 


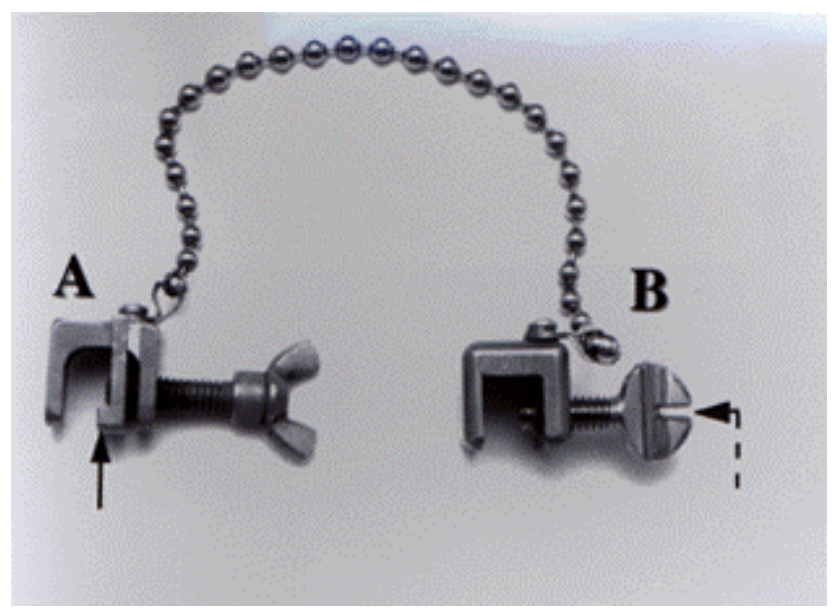

FIGURE 1

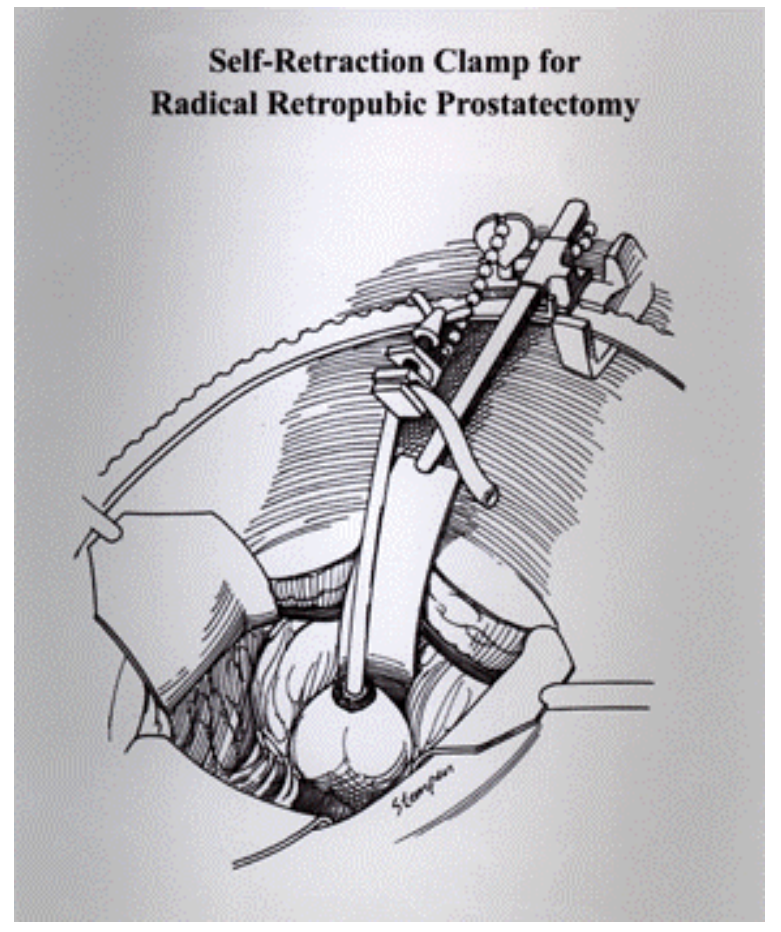

FIGURE 2

traction on the lateral pelvic fascia and the neurovascular bundles, as resection of the prostate gland proceeds cranially. In addition to applying constant steady traction on the posterior prostate gland during RRP, this traction device frees the surgeon's hand from manually retracting the Foley catheter.

\section{CONCLUSION}

In conclusion, a self-retraction clamp has been designed to apply constant steady traction on the prostate gland during dissection of the posterior prostatic fossa. The constant adjustable traction delineates the 
surgical planes between the prostate and the rectum. In addition, the surgeonís hand is freed from manually retracting the Foley catheter during dissection of the posterior prostatic fossa.

\section{REFERENCE}

1. Walsh, P.C.: Anatomic Radical Retropubic Prostatectomy: In: Campbell's Urology 7th edition. Edited by P. C. Walsh, A. B. Retik, T. A. Stamey, and E. D. Vaughan Jr., Philadelphia: W. B. Saunders, vol. 3, chapt. 86, pp. 2565-88, 1997.

This article should be referenced as follows:

Olumi, A.F. (2004) Self-retraction clamp for dissection of the posterior prostatic fossa during radical retropubic prostatectomy. TheScientificWorldJOURNAL 4 (S1), 260-262.

\section{Handling Editor:}

Anthony Atala, Principle Editor for Urology — a domain of TheScientificWorldJOURNAL. 


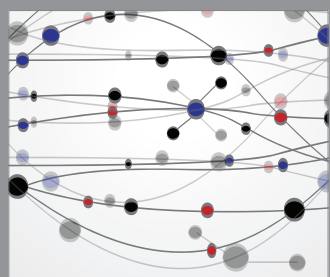

The Scientific World Journal
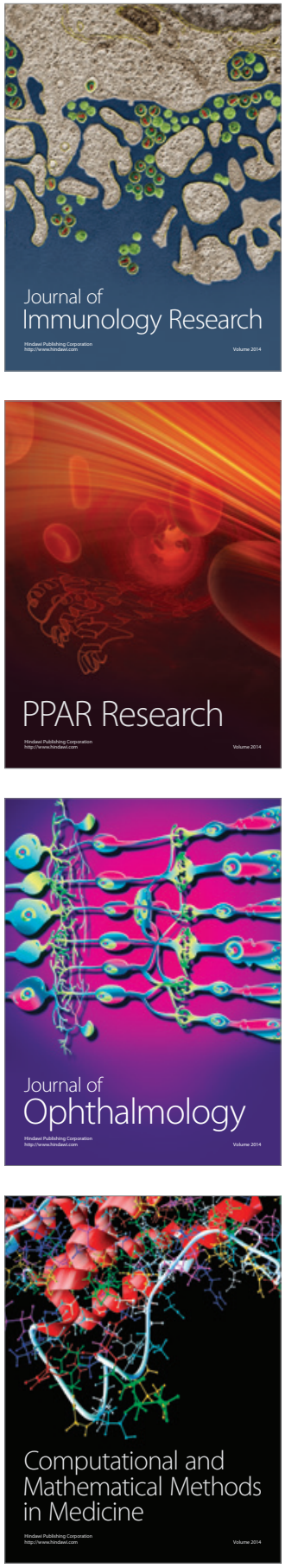

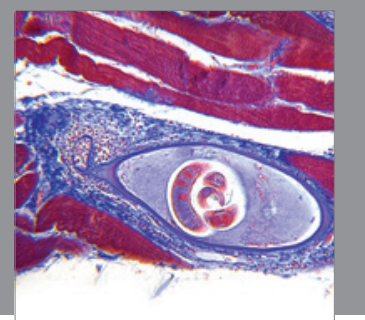

Gastroenterology

Research and Practice
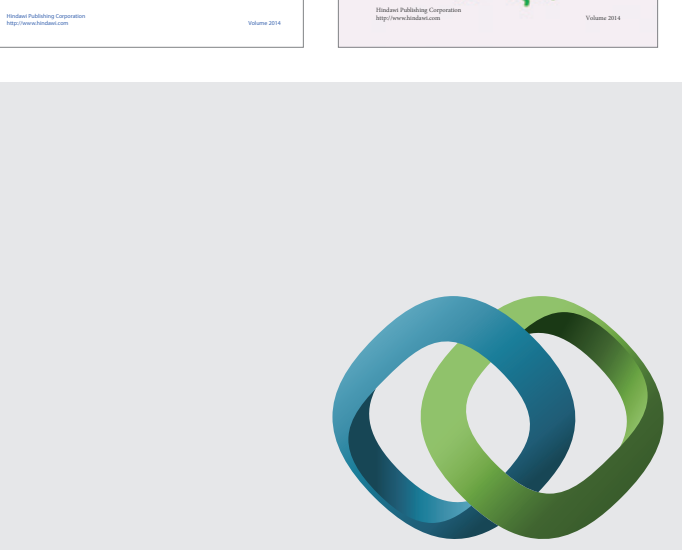

\section{Hindawi}

Submit your manuscripts at

http://www.hindawi.com
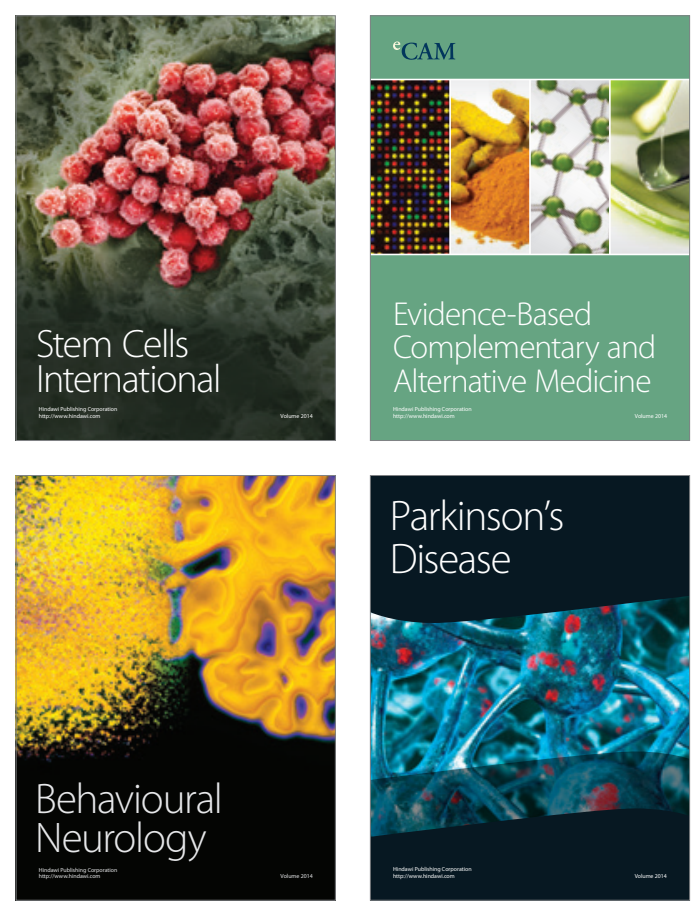

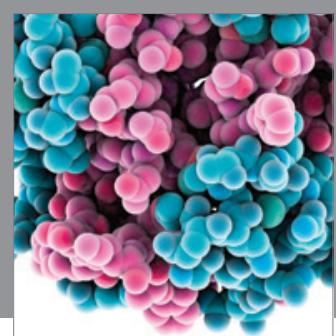

Journal of
Diabetes Research

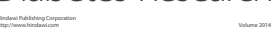

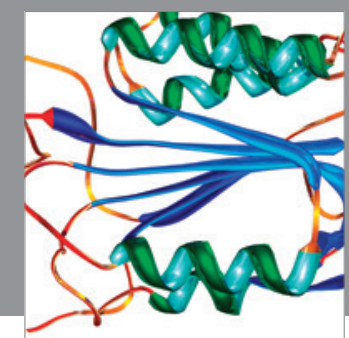

Disease Markers
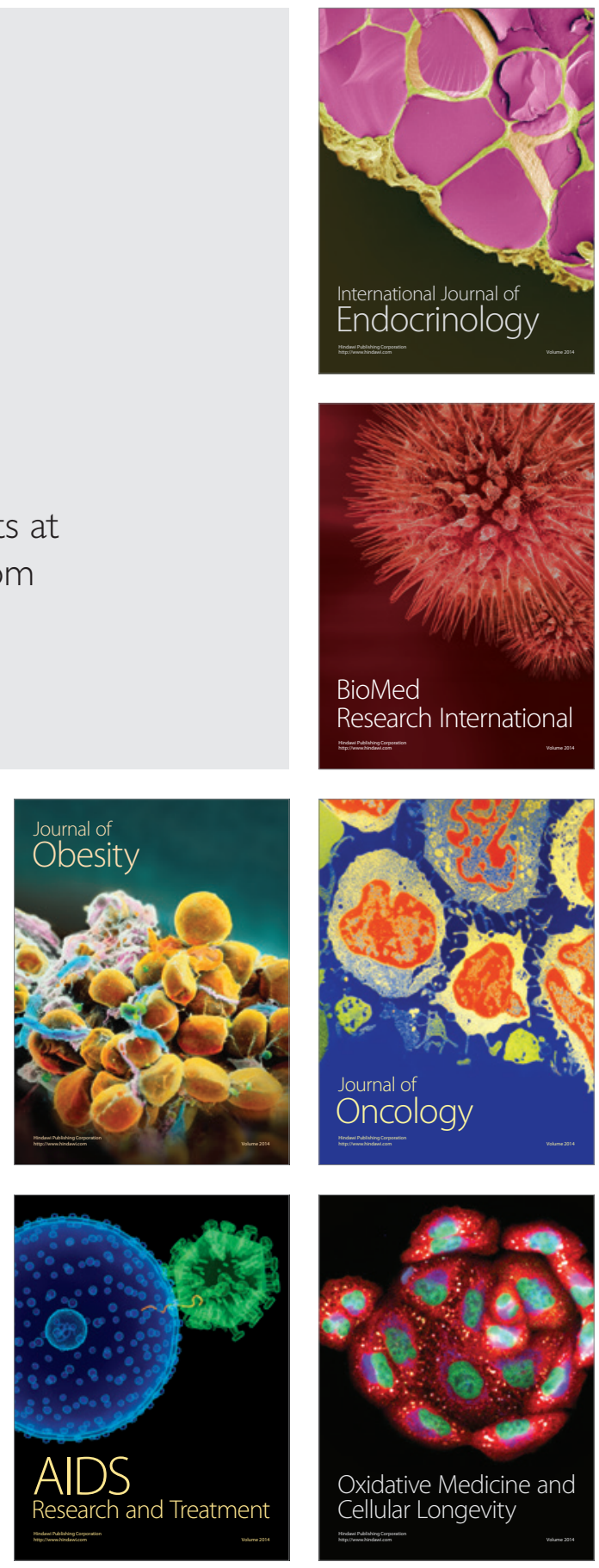